\title{
Gene profiling, biomarkers and pathways characterizing HCV-related hepatocellular carcinoma
}

\author{
Valeria De Giorgi1,2, Alessandro Monaco ${ }^{3}$, Andrea Worchech ${ }^{3,4,5}$, \\ MariaLina Tornesello ${ }^{1}$, Francesco Izzo ${ }^{6}$, Luigi Buonaguro1, \\ Francesco M Marincola ${ }^{3}$, Ena Wang ${ }^{3}$ and Franco M Buonaguro*1
}

Address: ${ }^{1}$ Molecular Biology and Viral Oncogenesis \& AIDS Refer. Center, Ist. Naz. Tumori "Fond. G. Pascale", Naples - Italy, ${ }^{2}$ Department of Chemistry, University of Naples "Federico II", Naples, Italy, ${ }^{3}$ Infectious Disease and Immunogenetics Section (IDIS), Department of Transfusion Medicine, Clinical Center and Trans-NIH Center for Human Immunology (CHI), National Institutes of Health, Bethesda, MD -USA, ${ }^{4}$ Genelux Corporation, Research and Development, San Diego Science Center, San Diego, CA, USA, ${ }^{5}$ Department of Biochemistry, Biocenter, University of Wuerzburg, Am Hubland, Wuerzburg, Germany and 'Div. of Surgery "D", Ist. Naz. Tumori "Fond. G. Pascale", Naples - Italy

Email: Valeria De Giorgi - valeriadegiorgi@tin.it; Alessandro Monaco - monacoal@cc.nih.gov; Andrea Worchech - worschecha@cc.nih.gov; MariaLina Tornesello - mltornesello@alice.it; Francesco Izzo - izzo@connect.it; Luigi Buonaguro - lbuonaguro@tin.it;

Francesco M Marincola - FMarincola@mail.cc.nih.gov; Ena Wang - ewang@mail.cc.nih.gov; Franco M Buonaguro* - irccsvir@unina.it

* Corresponding author

Published: 12 October 2009

Journal of Translational Medicine 2009, 7:85 doi:10.1 I86/1479-5876-7-85
Received: 2 July 2009

Accepted: 12 October 2009

This article is available from: http://www.translational-medicine.com/content/7/I/85

(C) 2009 De Giorgi et al; licensee BioMed Central Ltd.

This is an Open Access article distributed under the terms of the Creative Commons Attribution License (http://creativecommons.org/licenses/by/2.0), which permits unrestricted use, distribution, and reproduction in any medium, provided the original work is properly cited.

\begin{abstract}
Background: Hepatitis $\mathrm{C}$ virus (HCV) infection is a major cause of hepatocellular carcinoma $(\mathrm{HCC})$ worldwide. The molecular mechanisms of HCV-induced hepatocarcinogenesis are not yet fully elucidated. Besides indirect effects as tissue inflammation and regeneration, a more direct oncogenic activity of $\mathrm{HCV}$ can be postulated leading to an altered expression of cellular genes by early HCV viral proteins. In the present study, a comparison of gene expression patterns has been performed by microarray analysis on liver biopsies from HCV-positive HCC patients and HCV-negative controls.
\end{abstract}

Methods: Gene expression profiling of liver tissues has been performed using a high-density microarray containing 36 '000 oligos, representing $90 \%$ of the human genes. Samples were obtained from 14 patients affected by HCV-related HCC and $7 \mathrm{HCV}$-negative non-liver-cancer patients, enrolled at INT in Naples. Transcriptional profiles identified in liver biopsies from HCC nodules and paired non-adjacent non-HCC liver tissue of the same HCV-positive patients were compared to those from HCV-negative controls by the Cluster program. The pathway analysis was performed using the BRB-Array- Tools based on the "Ingenuity System Database". Significance threshold of $t$-test was set at $0.00 \mathrm{I}$.

Results: Significant differences were found between the expression patterns of several genes falling into different metabolic and inflammation/immunity pathways in HCV-related HCC tissues as well as the non$\mathrm{HCC}$ counterpart compared to normal liver tissues. Only few genes were found differentially expressed between HCV-related HCC tissues and paired non-HCC counterpart. 
Conclusion: In this study, informative data on the global gene expression pattern of HCV-related HCC and non-HCC counterpart, as well as on their difference with the one observed in normal liver tissues have been obtained. These results may lead to the identification of specific biomarkers relevant to develop tools for detection, diagnosis, and classification of HCV-related HCC.

\section{Introduction}

Hepatocellular carcinoma (HCC) is the most common liver malignancy as well as the third and the fifth cause of cancer death in the world in men and women, respectively [1-3]. As for other types of cancer, the etiology and pathogenesis of HCC is multifactorial and multistep [4]. The main risk factor for development of HCC are the hepatitis $B$ and $C$ virus (HBV and HCV) infection [5-8]. Non viral causes, such as toxins and drugs (i.e., alcohol, aflatoxins, microcystin, anabolic steroids), metabolic liver diseases (i.e., hereditary haemochromatosis, $\alpha 1$-antitrypsin deficiency), steatosis and non-alcoholic fatty liver diseases as well as diabetes, play a role in a minor number of cases [911]. The prevalence of HCC in Italy, and in Southern Italy in particular, is significantly higher compared to other Western countries. Hepatitis virus infection, long-term alcohol and tobacco consumption account for $87 \%$ of HCC cases in Italian population and, among these, 61\% of HCC are attributable to HCV. In particular, a recent seroprevalence surveillance study conducted in the general population of Southern Italy Campania Region reported a $7.5 \%$ positivity for $\mathrm{HCV}$ infection which peaked at $23.2 \%$ positivity in the 65 years or older age group [12]. The multistep progression to HCC, in particular the one associated to hepatitis virus, is characterized by a process including chronic liver injury, tissue inflammation, cell death, cirrhosis, regeneration, DNA damage, dysplasia and finally, HCC. In this multistep process, the cirrhosis represents the preneoplastic stage showing regenerative, dysplastic as well as HCC nodules [13].

The precise molecular mechanism underlying the progression of chronic hepatitis viral infections to HCC is currently unknown. Activation of cellular oncogenes, inactivation of tumor suppressor genes, overexpression of growth factors, telomerase activation and defects in DNA mismatch repair may contribute to the development of HCC [14-16]. In this framework, differential gene expression patterns accompanying different stages of growth, disease initiation, cell cycle progression, and responses to environmental stimuli provide important clues to this complex process.

DNA microarray enables investigators to study expression profile and activation of thousands of genes simultaneously. In particular, the identification of cancer-related stereotyped expression patterns might allow the elucida- tion of molecular mechanisms underlying cancer progression and provides important molecular markers for diagnostic purposes. This strategy has been recently used to profile global changes in gene expression in liver samples obtained from patients with HCV-related HCC [1719]. Several of these studies identified gene sets that may be useful as potential microarray-based diagnostic tools. However, the direct or indirect HCV role in HCC pathogenesis is still a controversial issue and additional efforts need to be made aimed to specifically dissect the relationship between stages of HCV chronic infection and progression to HCC.

The present study has been focused on investigating genes and pathways involved in viral carcinogenesis and progression to HCC in HCV-chronically infected patients.

\section{Materials and methods \\ Patient and Tissue Samples}

Liver biopsies from fourteen HCV-positive HCC patients and seven HCV-negative non-liver cancer control patients (during laparoscopic cholecystectomy) were obtained with informed consent at the liver unit of the INT "Pascale" in Naples. In particular, from each of the HCV-positive HCC patients, a pair of liver biopsies from HCC nodule and non-adjacent non-HCC counterpart were surgically excised. All liver biopsies were stored in RNA Later at $-80^{\circ} \mathrm{C}$ (Ambion, Austin, TX). Confirmation of the histopathological nature of the biopsies was performed by the Pathology lab at INT before the processing for RNA extraction. The non-HCC tissue from HCV-positive patient were an heterogeneous sample representing the prevalent liver condition of each subject (ranging from persistent HCV-infection to cirrhotic lesions). Furthermore, laboratory analysis confirmed that the 7 controls were seronegative for hepatitis $\mathrm{C}$ virus antibodies (HCV $\mathrm{Ab})$.

\section{Preparation of RNA, probe preparation, and microarray hybridization}

Samples were homogenized in disposable tissue grinders (Kendall, Precision). Total RNA was extracted by TRIzol solution (Life Technologies, Rockville, MD), and purity of the RNA preparation was verified by the 260:280 nm ratio (range, 1.8-2.0) at spectrophotometric reading with NanoDrop (Thermo Fisher Scientific, Waltham, MA). Integrity of extracted RNA was evaluated by Agilent 2100 Bioana- 
lyzer (Agilent Technologies, Palo Alto, CA), analyzing the presence of $28 \mathrm{~S}$ and $18 \mathrm{~S}$ ribosomal RNA bands as well as the $28 \mathrm{~S} / 18 \mathrm{~S}$ rRNA intensity ratio equal or close to 1.5 . In addition, phenol contamination was checked and a 260:230 nm ratio (range, 2.0-2.2) was considered acceptable.

Double-stranded cDNA was prepared from $3 \mu \mathrm{g}$ of total RNA (T-RNA) in $9 \mu$ DEPC -treated $\mathrm{H}_{2} \mathrm{O}$ using the Super script II Kit (Invitrogen) with a T7-(dT15) oligonucleotide primer. cDNA synthesis was completed at $42^{\circ} \mathrm{C}$ for $1 \mathrm{~h}$. Full-length dsDNA was synthesized incubating the produced cDNA with $2 \mathrm{U}$ of RNase-H (Promega) and $3 \mu \mathrm{l}$ of Advantage cDNA Polymerase Mix (Clontech), in Advantage PCR buffer (Clontech), in presence of $10 \mathrm{mM}$ dNTP and DNase-free water. dsDNA was extracted with phenolchloroform-isoamyl, precipitated with ethanol in the presence of $1 \mu \mathrm{l}$ linear acrylamide $(0.1 \mu \mathrm{g} / \mu \mathrm{l}$, Ambion, Austin, TX) and aRNA (amplified-RNA) was synthesized using Ambion's T7 MegaScript in Vitro Transcription Kit (Ambion, Austin, TX). aRNA recovery and removal of template dsDNA was achieved by TRIzol purification. For the second round of amplification, aliquots of $1 \mu \mathrm{g}$ of the aRNA were reverse transcribed into cDNA using $1 \mu \mathrm{l}$ of random hexamer under the conditions used in the first round. Second-strand cDNA synthesis was initiated by 1 $\mu \mathrm{g}$ oligo-dT-T7 primer and the resulting dsDNA was used as template for in vitro transcription of aRNA in the same experimental conditions as for the first round [20]. $6 \mu \mathrm{g}$ of this aRNA was used for probe preparation, in particular test samples were labeled with USL-Cy5 (Kreatech) and pooled with the same amount of reference sample (control donor peripheral blood mononuclear cells, PBMC,

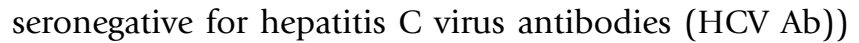
labeled with USL-Cy3 (Kreatech). The two labeled aRNA probes were separated from unincorporated nucleotides by filtration, fragmented, mixed and co-hybridized to a custom-made $36 \mathrm{~K}$ oligoarrays at $42^{\circ} \mathrm{C}$ for $24 \mathrm{~h}$. The oligo-chips were printed at the Immunogenetics Section Department of Transfusion Medicine, Clinical Center, National Institutes of Health (Bethesda, MD). After hybridization the slides were washed with $2 \times \mathrm{SSC} /$ $0.1 \%$ SDS for $1 \mathrm{~min}, 1 \times$ SSC for $1 \mathrm{~min}, 0.2 \times$ SSC for 1 min, $0.05 \times$ SSC for $10 \mathrm{sec}$., and dried by centrifugation at $800 \mathrm{~g}$ for 3 minutes at RT.

\section{Data Analysis}

Hybridized arrays were scanned at $10-\mu \mathrm{m}$ resolution with a GenePix 4000 scanner (Axon Instruments) at variable photomultiplier tube (PMT) voltage to obtain maximal signal intensities with less than $1 \%$ probe saturation. Image and data files were deposited at microarray data base (mAdb) at http://nciarray.nci.nih.gov and retrieved after median centered, filtering of intensity $(>200)$ and spot elimination (bad and no signal). Data were further analyzed using Cluster and TreeView software (Stanford University, Stanford, CA).

\section{Statistical Analysis}

Unsupervised Analysis

For this analysis, a low-stringency filtering was applied, selecting the genes differentially expressed in $80 \%$ of all experiments with a $>3$ fold change ratio in at least one experiment. 7'760 genes were selected for the analysis including the three groups of analyzed samples (the HCVrelated HCC, their non-HCC counterpart, as well as samples from the controls); 5'473 genes were selected for the analysis including the HCV-related HCC and normal control samples; 6'069 genes were selected for the analysis including the HCV-related non-HCC paired tissue and normal control samples. Hierarchical cluster analysis was conducted on these genes according to Eisen et al. [21]; differential expressed genes were visualized by Treeview and displayed according to the central method [22].

\section{Supervised Analysis}

Supervised class comparison was performed using the BRB ArrayTool developed at NCI, Biometric Research Branch, Division of Cancer Treatment and Diagnosis. Three subsets of genes were explored. The first subset included genes upregulated in HCV-related HCC compared to normal control samples, the second subset included genes upregulated in the HCV-related non-HCC counterpart compared with normal control samples, the third subset included genes upregulated in HCV-related HCC compared to the non-HCC paired liver tissue samples. Paired samples were analyzed using a two-tailed paired Student's $t$-test. Unpaired samples were tested with a two-tailed unpaired Student's $t$-test assuming unequal variance or with an $F$-test as appropriate. All analyses were tested for an univariate significance threshold set at a $p$ value $<0.01$ for the first subset of genes and at a $p$-value $<$ 0.001 for the second subset. Gene clusters identified by the univariate $t$-test were challenged with two alternative additional tests, an univariate permutation test (PT) and a global multivariate PT. The multivariate PT was calibrated to restrict the false discovery rate to $10 \%$. Genes identified by univariate $t$-test as differentially expressed ( $p$-value < 0.001 and $p$-value $<0.01$ ) and a PT significance $<0.05$ were considered truly differentially expressed. Gene function was assigned based on Database for Annotation, Visualization and Integrated Discovery (DAVID) and Gene Ontology http://www.geneontology.org/.

\section{Ingenuity pathway analysis}

The pathway analysis was performed using the gene set expression comparison kit implemented in BRB-ArrayTools. The human pathway lists determined by "Ingenuity 
A

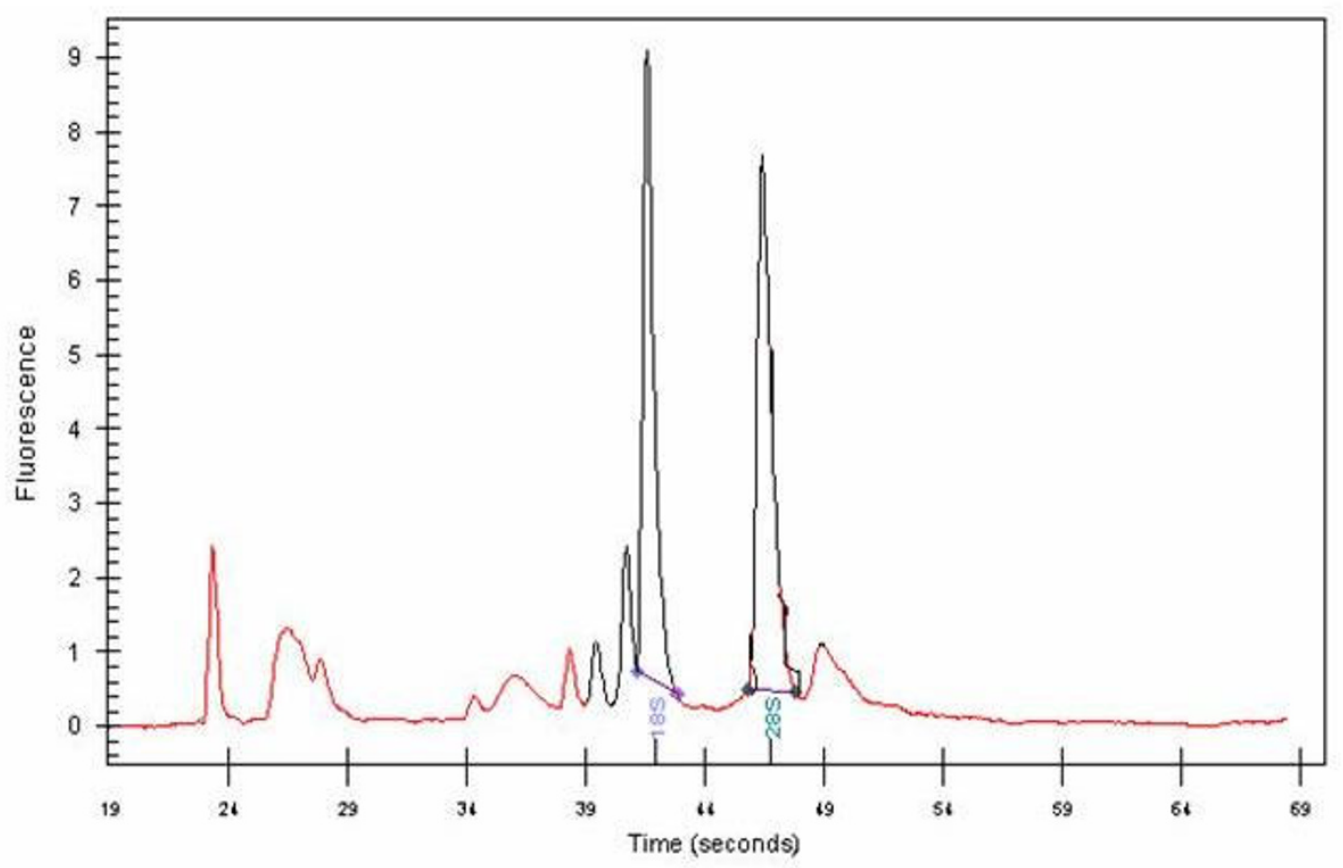

B
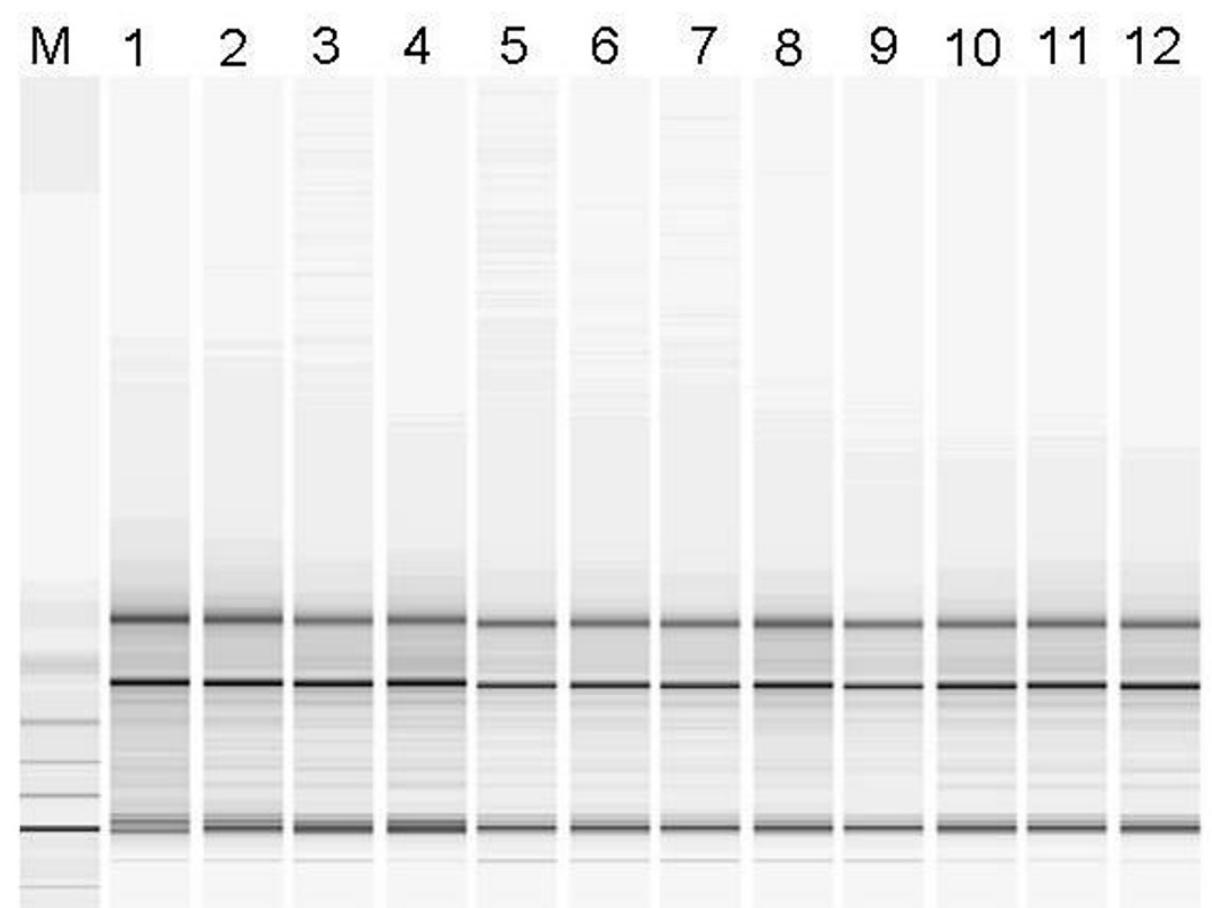

Figure I

Purity and integrity quality control of total extracted RNA. (A) Representative Electropherogram of total RNA extracted from samples included in the analysis. (B) Representative Gel image evaluation of RNA integrity and 28S/I8S rRNA ratio. 
System Database" was selected. Significance threshold of $t$-test was set at 0.001 . The Ingenuity Pathways Analysis (IPA) is a system that transforms large data sets into a group of relevant networks containing direct and indirect relationships between genes based on known interactions in the literature.

\section{Results \\ Quality Control}

The quality of extracted total RNA was verified by Agilent 2100 Bioanalyzer (Agilent Technologies, Palo Alto, CA), showing discrete $28 \mathrm{~S}$ and $18 \mathrm{~S}$ rRNA bands (Figure 1A) as well as a $28 \mathrm{~S} / 18 \mathrm{~S}$ rRNA intensity ratio equal or close to 1.5 which is considered appropriate for total RNA extracted from liver tissue biopsies ("Assessing RNA Quality", http:/ /www.ambion.com/techlib/tn/111/8.html). Based on this parameter, all extracted total RNA samples met the quality control criteria (Figure 1B).

\section{Unsupervised analysis is concordant with Pathological Classification}

The gene expression profiles of tissue samples from the three groups of analyzed samples (the HCV-related HCC, their non-HCC counterpart, as well as samples from con-
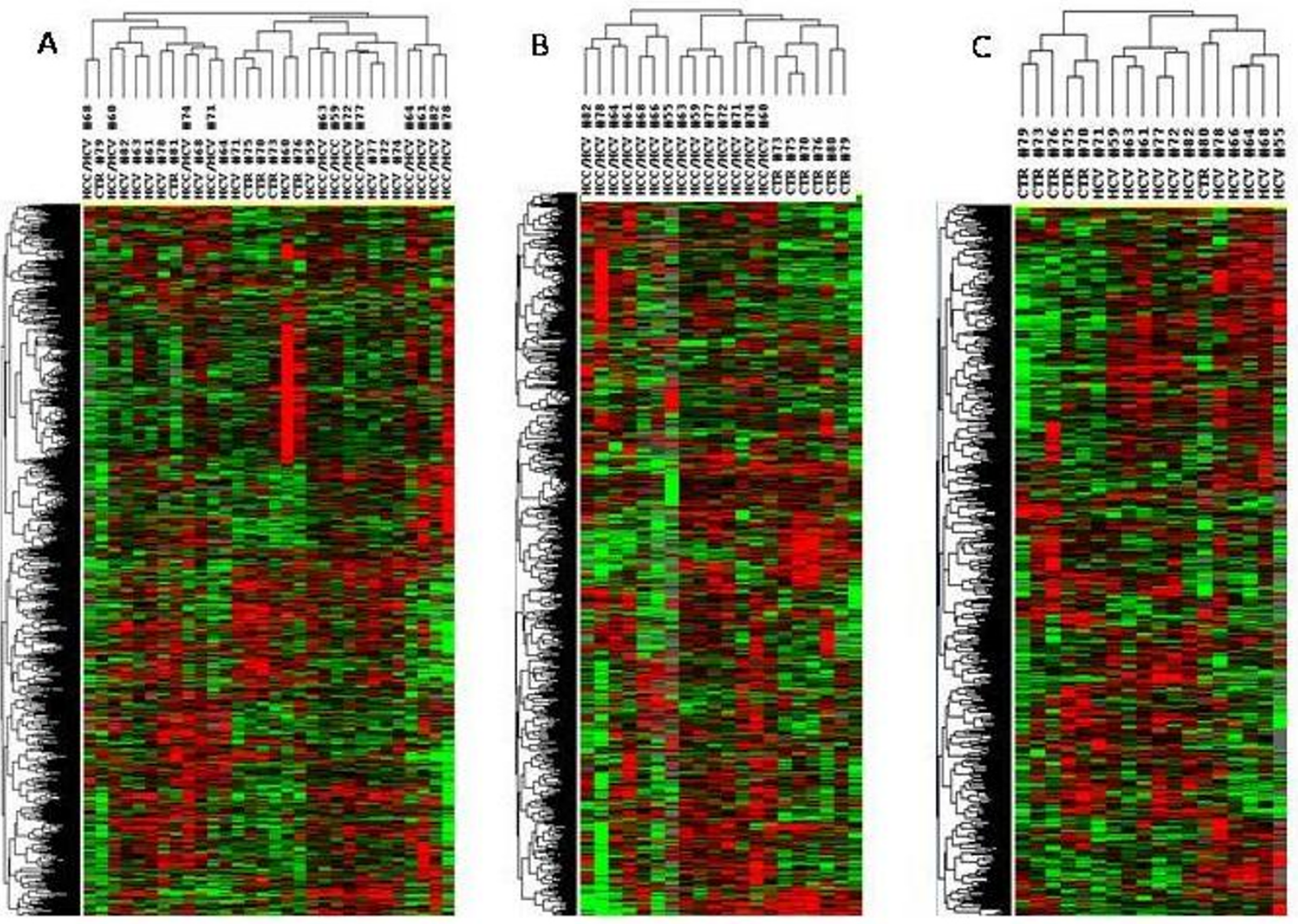

\section{Figure 2}

Unsupervised hierarchical clustering. Overall patterns of expression of genes across the I4 HCV-related HCC and nonHCC counterpart, as well as $7 \mathrm{HCV}$-negative control patients. Red indicates over-expression; green indicates under-expression; black indicates unchanged expression; gray indicates no detection of expression (intensity of both Cy 3 and Cy5 below the cutoff value). Each row represents a single gene; each column represents a single sample. The dendrogram at the left of matrix indicates the degree of similarity among the genes examined by expression patterns. The dendrogram at the top of the matrix indicates the degree of similarity between samples. Panel A, unsupervised analysis including all three set of samples; Panel B, unsupervised analysis including HCV-related HCC and normal control liver samples; Panel C, unsupervised analysis including HCV-related non-HCC counterpart and normal control liver samples. 
trol patients) were compared by an unsupervised analysis. No clear separation of the 3 different groups was observed, although control samples clustered mainly with samples from HCV-related non-HCC paired tissue, which includes dysplastic lesion in cirrhotic liver, representing a pre-neoplastic step (Figure 2A).

In order to identify genes differentially modulated in HCV-related lesions compared to normal liver tissue samples, an unsupervised analysis was then performed including only paired samples from HCV-related HCC and normal control samples or from the HCV-related nonHCC counterpart and control samples (Figures 2B and 2C). According to filtering described in Material and Methods, HCV-related HCC and normal control samples showed 5'473 genes differentially expressed, with a per- fect clustering according to histological characteristics (Figure 2B). Similarly, HCV-related non-HCC tissue and normal control samples showed 6'069 genes differentially expressed with a perfect clustering according to histological characteristics also in this case (Figure 2C). The only exception to this pattern is represented by the normal control sample (CTR\#80) which did not fall in the control cluster (CTR).

\section{Supervised analysis}

The supervised analysis was performed comparing pairs of gene sets using an unpaired Student's $t$-test with a cut-off set at $p<0.01$.

The analysis comparing gene sets in liver tissues from HCV-related HCC and normal controls identified 825

Table I: The first 40 up-regulated genes in HCV-related HCC

\begin{tabular}{|c|c|c|}
\hline $\mathbf{N}^{\circ}$ & Gene Name & Description \\
\hline 1 & RYBP & RINGI and YYI binding protein (RYBP) \\
\hline 2 & ATPIB3 & ATPase, $\mathrm{Na}+/ \mathrm{K}+$ transporting, beta 3 polypeptide \\
\hline 3 & TMC & transmembrane channel-like 7 (TMC7) \\
\hline 4 & ZNF567 & zinc finger protein 567 (ZNF567 \\
\hline 5 & GPRI08 & G protein-coupled receptor I08 (GPR I08), transcript variant I \\
\hline 6 & CDI9 & CDI9 molecule \\
\hline 7 & SPINKI & serine peptidase inhibitor, Kazal type I \\
\hline 8 & CDC2L6 & cell division cycle 2-like 6 (CDK8-like) \\
\hline 9 & RSRCI & arginine/serine-rich coiled-coil I (RSRCI) \\
\hline 10 & METAP & methionyl aminopeptidase I \\
\hline II & GPC3 & glypican 3 \\
\hline 12 & SNHGII & Small nucleolar RNA host gene (non-protein coding) II \\
\hline 13 & RYI & putative nucleic acid binding protein RY-I (RYI) \\
\hline 14 & CRELD2 & cysteine-rich with EGF-like domains 2 (CRELD2) \\
\hline 15 & GLUL & glutamate-ammonia ligase (glutamine synthetase) \\
\hline 16 & SERPINBI & serpin peptidase inhibitor, clade B (ovalbumin), member I (SERPINBI) \\
\hline 17 & TRMT6 & tRNA methyltransferase 6 homolog (S. cerevisiae) \\
\hline 18 & UNCI3D & unc-I 3 homolog D (C. elegans) (UNCI3D) \\
\hline 19 & E4FI--E4F & E4F transcription factor I (E4FI) \\
\hline 20 & SLC22A2 & solute carrier family 22 (organic cation transporter), member 2 (SLC22A2) \\
\hline 21 & $\mathrm{CNIH} 4$ & cornichon homolog 4 (Drosophila) (CNIH4) \\
\hline 22 & TKI & thymidine kinase I, soluble (TKI) \\
\hline 23 & MAFB & v-maf musculoaponeurotic fibrosarcoma oncogene homolog B (avian) \\
\hline 24 & PPPICB & protein phosphatase I, catalytic subunit, beta isoform (PPPICB), transcript variant 3 \\
\hline 25 & DNTTIP2 & deoxynucleotidyltransferase, terminal, interacting protein 2 (DNTTIP2) \\
\hline 26 & ARID4B & AT rich interactive domain 4B (RBPI-like) (ARID4B), transcript variant I \\
\hline 27 & SMARCC2 & SWI/SNF related, matrix associated, actin dependent regulator of chromatin, subfamily c, \\
\hline 28 & PROI386 & PROI386 protein \\
\hline 29 & TRIOBP & TRIO and F-actin binding protein (TRIOBP), transcript variant I \\
\hline 30 & VARS & valyl-tRNA synthetase \\
\hline 31 & ITGA5 & integrin, alpha 5 (fibronectin receptor, alpha polypeptide) \\
\hline 32 & TERFI & telomeric repeat binding factor (NIMA-interacting) I (TERFI), transcript variant 2 \\
\hline 33 & PURA & purine-rich element binding protein A (PURA) \\
\hline 34 & TUBAIB & tubulin, alpha Ib \\
\hline 35 & SNRPE & small nuclear ribonucleoprotein polypeptide $\mathrm{E}$ \\
\hline 36 & RRAGD & Ras-related GTP binding D \\
\hline 37 & VWF & von Willebrand factor \\
\hline 39 & GLRX3 & glutaredoxin 3 (GLRX3) \\
\hline 40 & ILF2 & interleukin enhancer binding factor 2, $45 \mathrm{kDa}$ \\
\hline
\end{tabular}




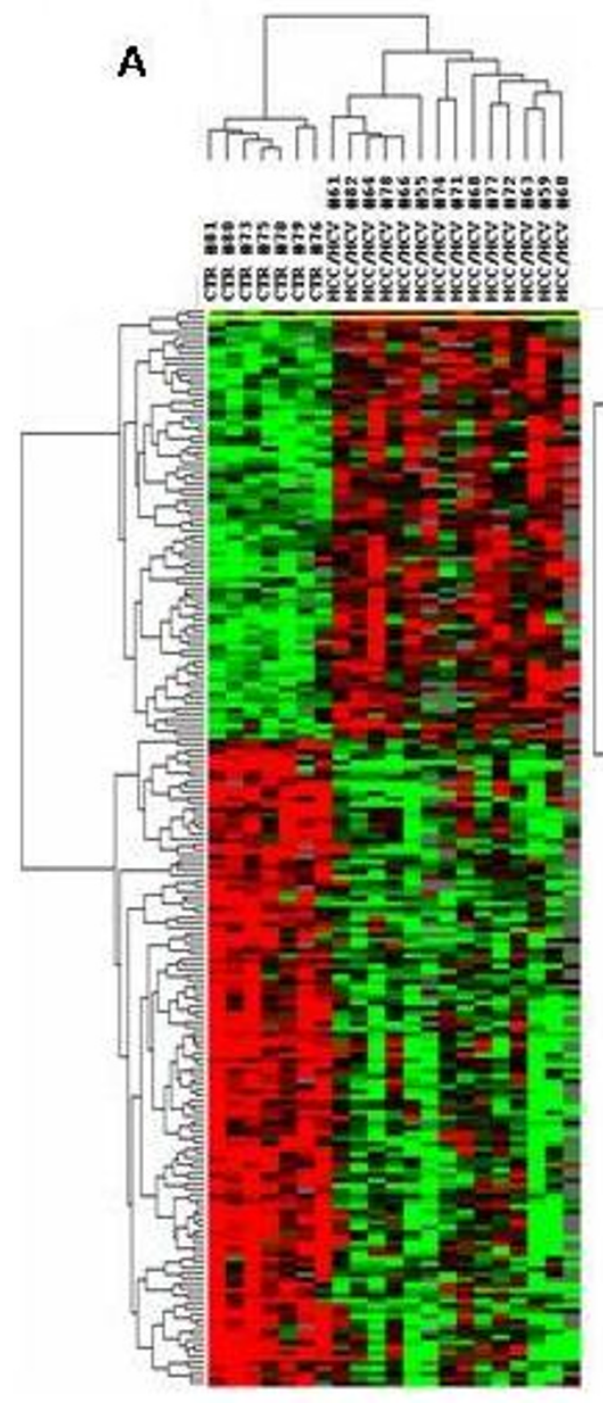

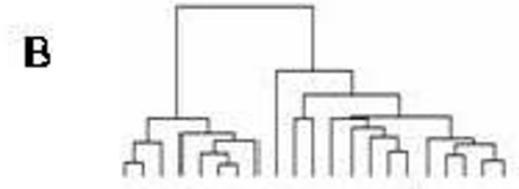
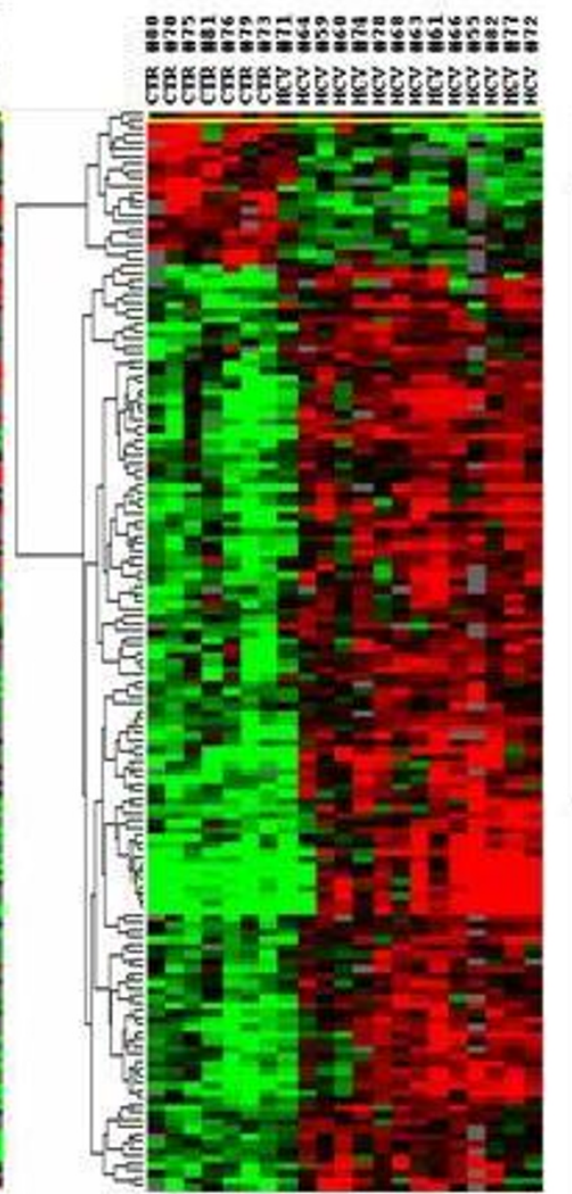

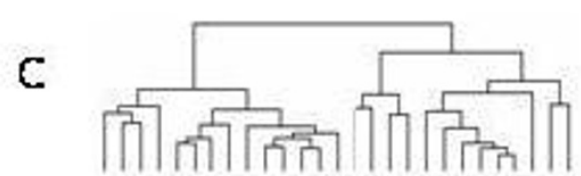

$:$

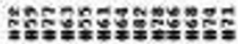

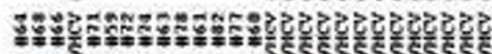

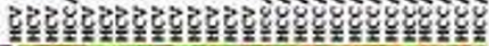

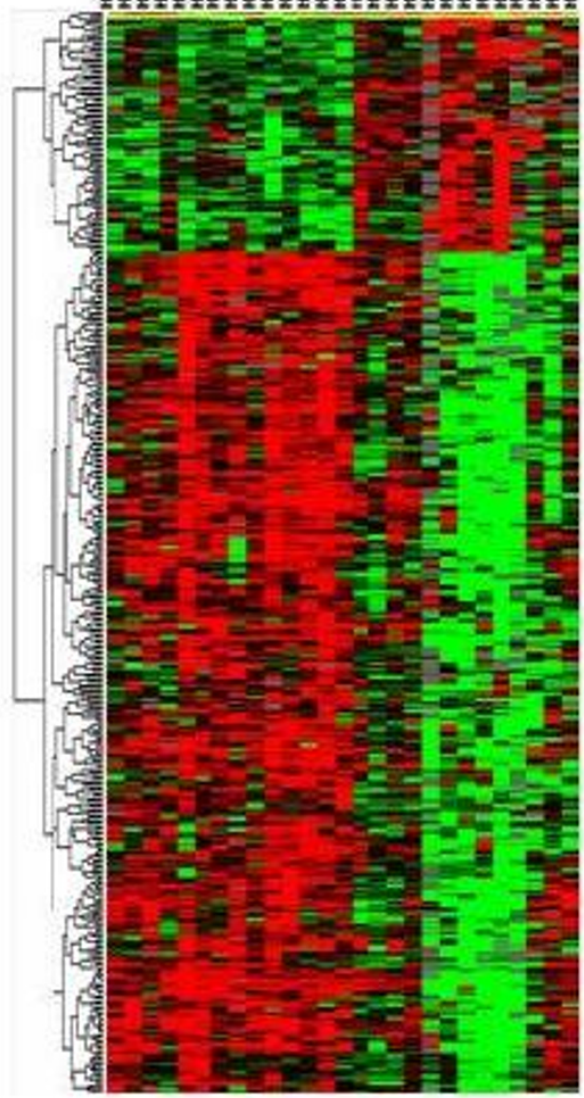

Figure 3

Heat map of the gene signature, identified by Class Comparison Analysis. Panel A, analysis including HCV-related $\mathrm{HCC}$ and normal control liver samples; Panel B, analysis including HCV-related non-HCC liver tissues and control liver samples; Panel C, analysis including HCV-related HCC and HCV-related non-HCC counterpart liver samples. The expression pattern of the genes is shown each row represents a single gene.

genes differentially expressed. Among them, 465 were shown to be up-regulated and 360 down-regulated in HCV-related HCC liver tissues (Figure 3A). The first 40 genes showing the highest fold of up-regulation are listed in Table 1.

The analysis comparing gene sets in liver tissues from HCV-related non-HCC tissue and controls identified 151 genes differentially expressed. Among them, 127 were shown to be up-regulated and 24 down-regulated in HCVrelated non-HCC liver tissues (Figure 3B). The first 40 genes showing the highest fold of up-regulation are listed in Table 2.
The analysis comparing gene sets in liver tissues from HCV-related HCC and HCV-related non-HCC counterpartidentified 383 genes differentially expressed. Among them, 83 were shown to be up-regulated and 300 downregulated in HCV-related HCC liver tissues (Figure 3C). The first 40 genes showing the highest fold of up-regulation are listed in Table 3.

\section{Ingenuity pathway analysis}

The pathway analysis was performed including the genes found up-regulated in the supervised comparisons, using the gene set expression comparison kit implemented in BRB-Array- Tools. The human pathway lists determined 
Table 2: The first 40 up-regulated genes in HCV-related non-HCC counterpart

\begin{tabular}{|c|c|c|}
\hline $\mathbf{N}^{\circ}$ & Gene Name & Description \\
\hline I & NMNAT3 & nicotinamide nucleotide adenylyltransferase 3 (NMNAT3). \\
\hline 2 & OASL & 2'-5'-oligoadenylate synthetase-like (OASL), transcript variant 2 \\
\hline 3 & TMPRSS3 & transmembrane protease, serine 3 (TMPRSS3), transcript variant $C$ \\
\hline 4 & MFSD7 & major facilitator superfamily domain containing 7 (MFSD7) \\
\hline 5 & AEBPI & AE binding protein I (AEBPI), mRNA. \\
\hline 6 & UBD & ubiquitin $\mathrm{D}(\mathrm{UBD})$ \\
\hline 7 & SI00A4 & SI00 calcium binding protein A4 (SI00A4), transcript variant I \\
\hline 8 & Clorfi5I & chromosome I open reading frame I5I (ClorfI5I) \\
\hline 9 & CRIPI & Cysteine-rich protein I (intestinal) \\
\hline 10 & ASCC3 & activating signal cointegrator I complex subunit 3 \\
\hline II & ZNF27I & zinc finger protein 27I (ZNF27I), transcript variant 2 \\
\hline 12 & ANXA4 & annexin A4 (ANXA4) \\
\hline 13 & NMI & $\mathrm{N}$-myc (and STAT) interactor (NMI) \\
\hline 14 & UBE2L6 & ubiquitin-conjugating enzyme E2L 6 (UBE2L6), transcript variant I \\
\hline 15 & B2 $M$ & beta-2-microglobulin (B2 M) \\
\hline 16 & HLA-F & Major histocompatibility complex, class I, F \\
\hline 17 & PSMB9 & Proteasome (prosome, macropain) subunit, beta type, 9 \\
\hline 18 & TAPI & transporter I, ATP-binding cassette, sub-family B (MDR/TAP) \\
\hline 19 & PSME2 & proteasome (prosome, macropain) activator subunit 2 (PA28 beta) \\
\hline 20 & IFII6 & interferon, gamma-inducible protein 16 \\
\hline 21 & $\mathrm{IFI} 27$ & interferon, alpha-inducible protein 27 \\
\hline 22 & ARHGAP9 & Rho GTPase activating protein 9 \\
\hline 23 & RABGAPIL & RAB GTPase activating protein I-like \\
\hline 24 & TNKI & tyrosine kinase, non-receptor \\
\hline 25 & DEF6 & differentially expressed in FDCP 6 homolog (mouse) \\
\hline 26 & BTN3A3 & butyrophilin, subfamily 3 , member $A 3$ \\
\hline 27 & RPS6KAI & ribosomal protein $\$ 6$ kinase, $90 \mathrm{kDa}$, polypeptide I \\
\hline 28 & CD24 & CD24 molecule \\
\hline 29 & PARPIO & poly (ADP-ribose) polymerase family, member 10 \\
\hline 30 & APOL3 & apolipoprotein L, 3 (APOL3), transcript variant alpha/d \\
\hline 31 & STAT & signal transducer and activator of transcription I, $91 \mathrm{kDa}$ \\
\hline 32 & ANKRDIO & Ankyrin repeat domain 10 \\
\hline 33 & CKB & creatine kinase, brain (CKB) \\
\hline 34 & H2AFZ & $\mathrm{H} 2 \mathrm{~A}$ histone family, member $\mathrm{Z}$ \\
\hline 35 & PSMB9 & proteasome (prosome, macropain) subunit, beta type, 9 \\
\hline 36 & RARRES3 & retinoic acid receptor responder (tazarotene induced) 3 \\
\hline 37 & RGSIO & regulator of G-protein signaling 10 (RGSI0), transcript variant 2 \\
\hline 38 & TUBB & tubulin, beta \\
\hline 39 & NOL3 & nucleolar protein 3 (apoptosis repressor with CARD domain) \\
\hline 40 & CD7 & CD74 molecule, major histocompatibility complex, class II invariant chain \\
\hline
\end{tabular}

by "Ingenuity System Database" was selected. Significance threshold of $t$-test was set at 0.001 . Samples from HCVrelated non-HCC liver tissue showed strong up-regulation of genes involved in Antigen Presentation, Protein Ubiquitination, Interferon signaling, IL-4 signaling, Bacteria and Viruses cell cycle and chemokine signaling pathways. Samples from HCV-related HCC showed strong up-regulation of genes involved in Metabolism, Aryl Hydrocarbon receptor signaling, 14-3-3 mediated signaling and protein Ubiquitination pathways. Significant pathways were listed respectively in Figures 4, 5, 6 and 7.

\section{Discussion}

The pathogenetic mechanisms leading to HCC development in HCV chronic infection are not yet fully elucidated. In particular, besides inducing liver tissue inflammation and regeneration, which ultimately may result in cellular transformation and HCC development, HCV may play a more direct oncogenic activity inducing an altered expression of cellular genes. To this aim, global gene expression profile can identify specific genes differentially expressed and provide powerful insights into mechanisms regulating the transition from pre-neoplastic to fully blown neoplastic proliferation $[23,24]$. 
Table 3: The first 40 up-regulated genes in HCV-related HCC

\begin{tabular}{|c|c|c|}
\hline $\mathbf{N}^{\circ}$ & Gene Name & Description \\
\hline I & CAPG & capping protein (actin filament), gelsolin-like \\
\hline 2 & OCC-I & PREDICTED: misc_RNA (OCC-I) \\
\hline 3 & EED & embryonic ectoderm development (EED), transcript variant I \\
\hline 4 & RPLPO & ribosomal protein, large, PO (RPLP0), transcript variant I \\
\hline 5 & RPLPOP2 & ribosomal protein, large, $\mathrm{PO}$ pseudogene 2 \\
\hline 6 & APIS2 & adaptor-related protein complex I, sigma 2 subunit \\
\hline 7 & RRAGD & Ras-related GTP binding D (RRAGD) \\
\hline 8 & PFDN4 & prefoldin subunit 4 (PFDN4) \\
\hline 9 & CCDCI04 & coiled-coil domain containing 104 (CCDCI04) \\
\hline 10 & C7orf28B & chromosome 7 open reading frame 28B \\
\hline II & PSIPI & PC4 and SFRSI interacting protein I (PSIPI), transcript variant 2. \\
\hline 12 & LPCATI & lysophosphatidylcholine acyltransferase I \\
\hline 13 & FSCN3 & fascin homolog 3 , actin-bundling protein, testicular \\
\hline 14 & RAB24 & RAB24, member RAS oncogene family \\
\hline 15 & ZNF446 & zinc finger protein 446 (ZNF446) \\
\hline 16 & SECIIB & PREDICTED: SECII homolog B (S. cerevisiae) \\
\hline 17 & ZNF586 & zinc finger protein 586 (ZNF586) \\
\hline 18 & SCNMI & sodium channel modifier I \\
\hline 19 & SF3AI & splicing factor $3 \mathrm{a}$, subunit I, $120 \mathrm{kDa}$ \\
\hline 20 & RUFYI & RUN and FYVE domain containing I \\
\hline 21 & TRIM55 & tripartite motif-containing 55 \\
\hline 22 & GOLGA4 & golgi autoantigen, golgin subfamily a \\
\hline 23 & GPATCH4 & G patch domain containing 4 (GPATCH4), transcript variant I \\
\hline 24 & THOPI & thimet oligopeptidase I \\
\hline 25 & TUBB2C & tubulin, beta $2 \mathrm{C}$ (TUBB2C) \\
\hline 26 & PHLDB3 & Pleckstrin homology-like domain, family B \\
\hline 27 & FAMI04A & family with sequence similarity 104 , member $\mathrm{A}$ \\
\hline 28 & FASTK & Fas-activated serine/threonine kinase \\
\hline 29 & EIF2AK4 & eukaryotic translation initiation factor 2 alpha kinase 4 \\
\hline 30 & ZFP4I & ZFP4 I--zinc finger protein 4 I homolog (mouse) \\
\hline 31 & PRKRIPI & PRKR interacting protein I (ILII inducible) \\
\hline 32 & DSTN & destrin (actin depolymerizing factor) \\
\hline 33 & PHIP & pleckstrin homology domain interacting protein (PHIP) \\
\hline 34 & NUCKSI & nuclear casein kinase and cyclin-dependent kinase substrate I \\
\hline 35 & TNRC8 & Trinucleotide repeat containing 8 \\
\hline 36 & $\mathrm{CCDCI} 32$ & coiled-coil domain containing 132 \\
\hline 37 & EPRS & glutamyl-prolyl-tRNA synthetase \\
\hline 39 & HISTIH4C & histone cluster $\mathrm{I}, \mathrm{H} 4 \mathrm{c}$ \\
\hline 40 & CDCA8 & cell division cycle associated 8 \\
\hline
\end{tabular}

In the present study, the differential gene expression was evaluated by microarray analysis on liver tissues obtained from fourteen HCV-positive HCC patients and seven HCV-negative control patients. In particular, from each of the HCV-positive HCC patients, a pair of liver biopsies from HCC nodule and non-HCC non adjacent counterpart were surgically excised.

The unsupervised analysis didn't show a clear separation of samples from the 3 different groups (HCV-related HCC, their non-HCC counterpart, as well as control patients), suggesting the lack of a clear-cut distinct gene signature pattern. Nevertheless, normal control samples, with the exception of CTR\#76 sample, grouped in a single cluster close to samples from HCV-related paired nonHCC samples. The latter, in fact, comprise several nonHCC pathological stages including dysplastic, not fully transformed lesions, representing pre-neoplastic step in the progression to HCC and should still retain a gene signature pattern closer to normal than to transformed cell physiology. On the contrary, the unsupervised analysis including only one of the HCV-related liver tissues (HCC or non-HCC counterpart) and normal controls showed a clear-cut segregation of the pathological from the control cluster, indicating the identification of specific gene signature patterns peculiar to the HCV-related pre-neoplastic (non-HCC) and neoplastic (HCC) tissues compared to normal controls. 


\begin{tabular}{|l|l|}
\hline a HCC vs CTR p01 up in HCC \\
\hline
\end{tabular}

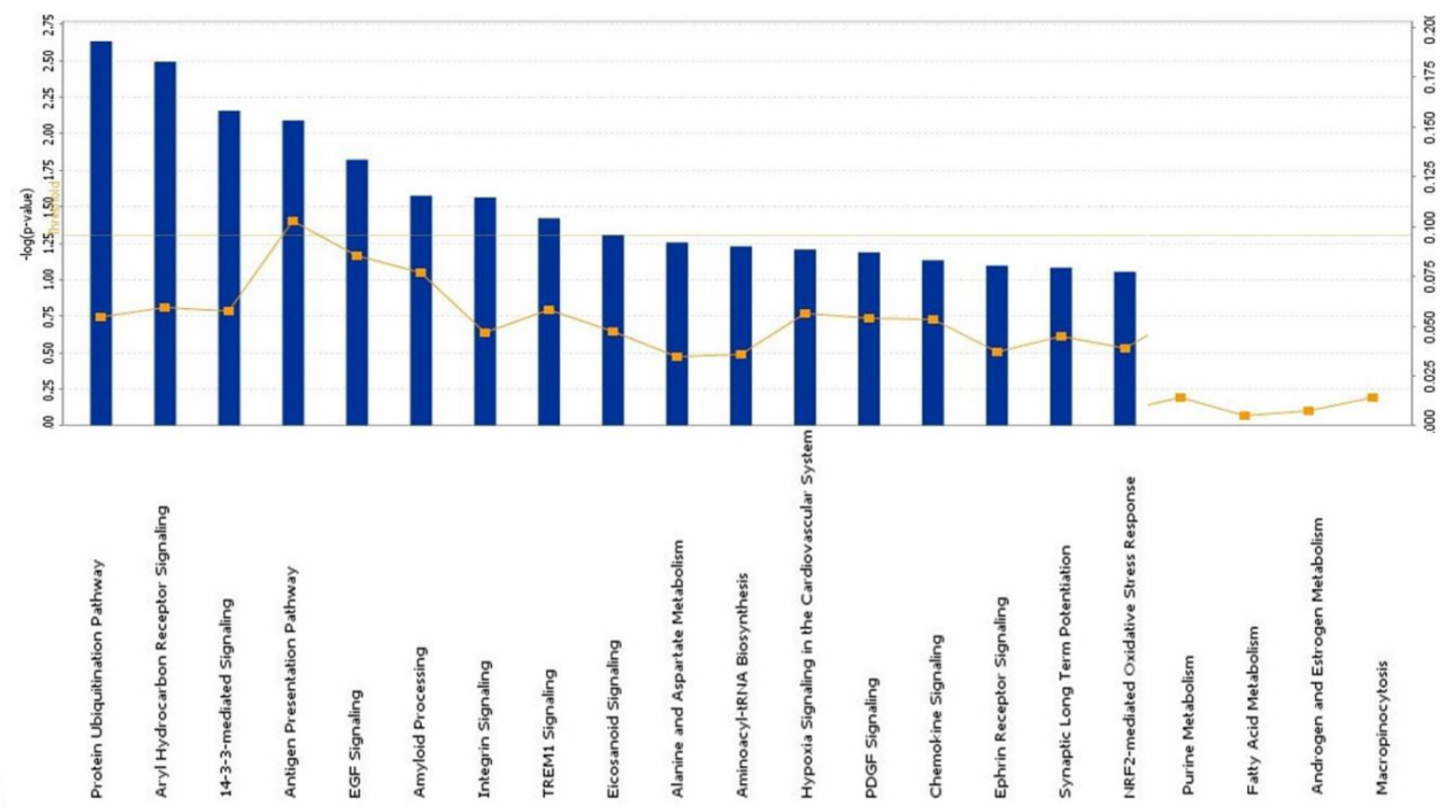

Figure 4

Significant pathways at the nominal $0.0 \mathrm{I}$ level of the unpaired Student's $t$-test. The human pathway lists determined by "Ingenuity System Database" in HCV-related HCC samples.

A supervised analysis was performed by pairwise comparison between samples of the three groups analyzed in the present study. The results indicated that the HCV-related HCC liver tissues showed 825 genes differentially expressed compared to controls, of which 465 were upregulated and 360 down-regulated. The HCV-related nonHCC liver tissues showed 151 genes differentially expressed compared to controls, of which 127 were upregulated and 24 down-regulated. The HCV-related HCC liver tissues showed 383 genes differentially expressed compared to HCV-related non-HCC counterpart, of which 83 were up-regulated and 300 down-regulated. In each of these independent class comparison analysis, the differentially expressed genes were selected based on a 3fold difference at a significance $p$-value $<0.01$.

The up-regulated genes identified within the individual class comparison analysis were further evaluated and classified by a pathway analysis, according to the "Ingenuity System Database".

The genes up-regulated in samples from HCV-related HCC are classified in metabolic pathways, and the most represented are the Aryl Hydrocarbon receptor signaling (AHR) and, protein Ubiquitination pathways, which have been previously reported to be involved in cancer, and in particular in HCC, progression.

The Aryl Hydrocarbon receptor signal transduction Pathway (AHR) is involved in the activation of the cytosolic aryl hydrocarbon receptor by structurally diverse xenobiotic ligands (including dioxin, and polycyclic or halogenated aromatic hydrocarbons) and mediating their toxic and carcinogenic effects $[25,26]$. More recently AHR pathway has been shown to be involved in apoptosis, cell cycle regulation, mitogen-activated protein kinase cascades [27]. In particular, studies on liver tumor promotion have shown that dioxin-induced AHR activation mediates clonal expansion of initiated cells by inhibiting apoptosis and bypassing AHR-dependent cell cycle arrest [28]. Furthermore, it has been shown that changes in mRNA expression of specific genes in the AHR pathway are linked to progression of HCV-associated hepatocellular carcinoma [29]. Moreover, the HCV-induced AHR signal transduction pathway, could be directly involved in the 
Protein Ubiquitination Pathway

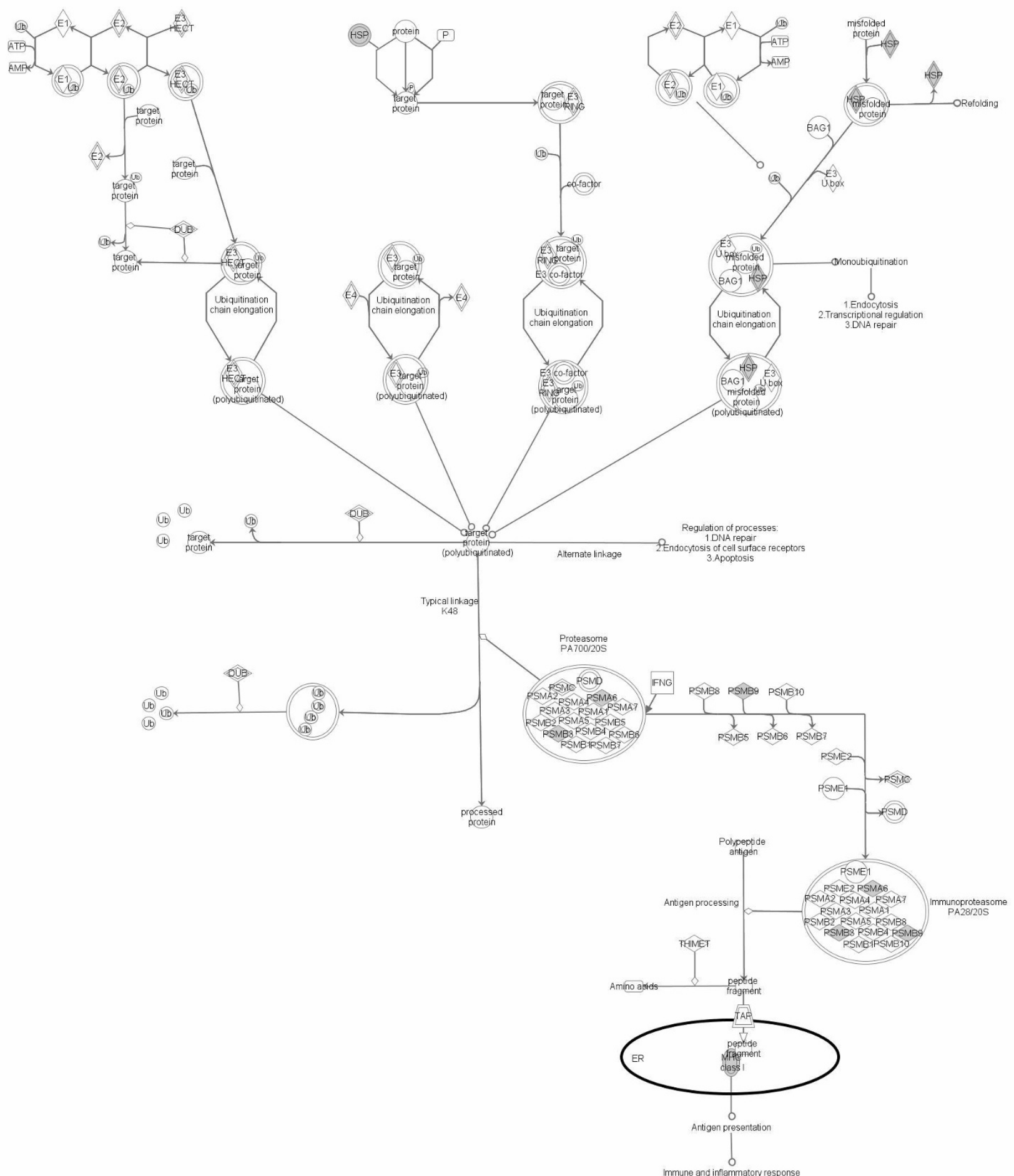

Figure 5

Significant pathways at the nominal $0.0 I$ level of the unpaired Student's $t$-test. The I top-scoring pathway of genes upregulated IPA image. 


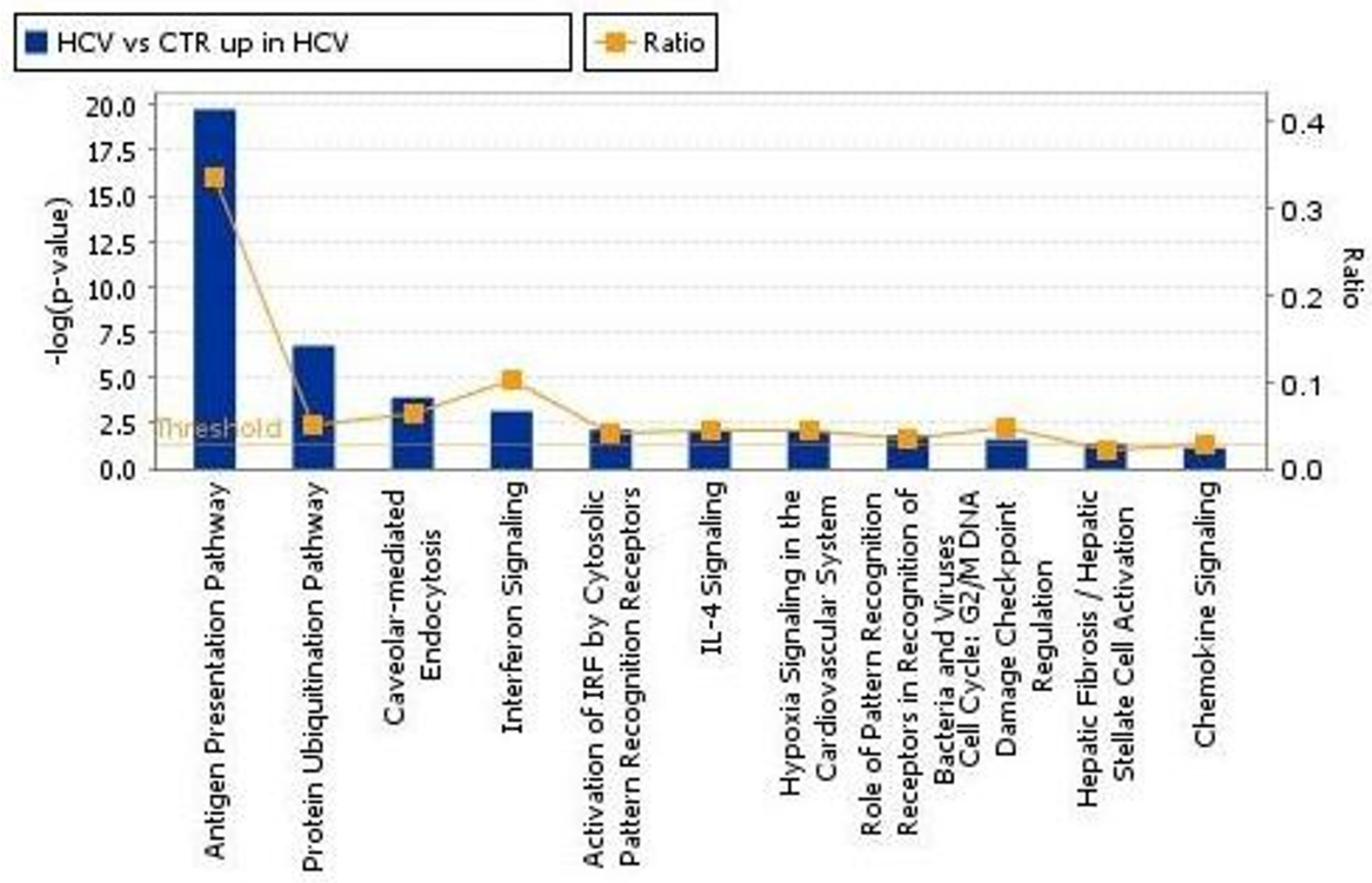

Figure 6

Significant pathways at the nominal $\mathbf{0 . 0 0}$ I level of the unpaired Student's t-test. The human pathway lists determined by "Ingenuity System Database" in HCV-related non-HCC samples.

increased severity of hepatic lesions in patients with chronic hepatitis $C$ induced by smoking $[30,31]$.

The ubiquitin and ubiquitin-related proteins of the ubiquitination pathway play instrumental roles in cell-cycle regulation [32] as well as cell death/apoptosis [33] through modification of target proteins. In particular, ubiquitin-like proteins, i.e. FAT10, has been reported to bind non-covalently to the human spindle assembly checkpoint protein, MAD2 [34], which is responsible for maintaining spindle integrity during mitosis [35] and whose inhibited function has been associated with chromosomal instability [36,37]. Moreover, FAT10 overexpression has been previously shown in hepatocellular carcinoma [38].

The genes up-regulated in samples from HCV-related nonHCC tissue are classified in several pathways prevalently associated to inflammation and native/adaptive immunity and most of the overexpressed genes belong to the Antigen Presentation pathway. Considering the chronic
HCV infection, these result could be unexpected and contradictory, since a reduced native and/or adaptive specific immune response would represent a very much favorable environment for the virus. Nevertheless, these findings, which confirm also a recent report by others [39], could explain the generic massive inflammation and immunopathological tissue damage characteristic of HCV-related cirrhosis [40].

In this study, informative data on the global gene expression pattern in HCV-related HCC as well as HCV-related non-HCC counterpart liver tissues have been obtained compared to normal controls. These data, which need further confirmation studies on a larger set of samples and also at protein level, may be extremely helpful for the identification of exclusive activation markers to characterize gene expression programs associated with progression of HCV-related lesions to HCC.

\section{Competing interests}

The authors declare that they have no competing interests. 
Antigen Presentation Pathway

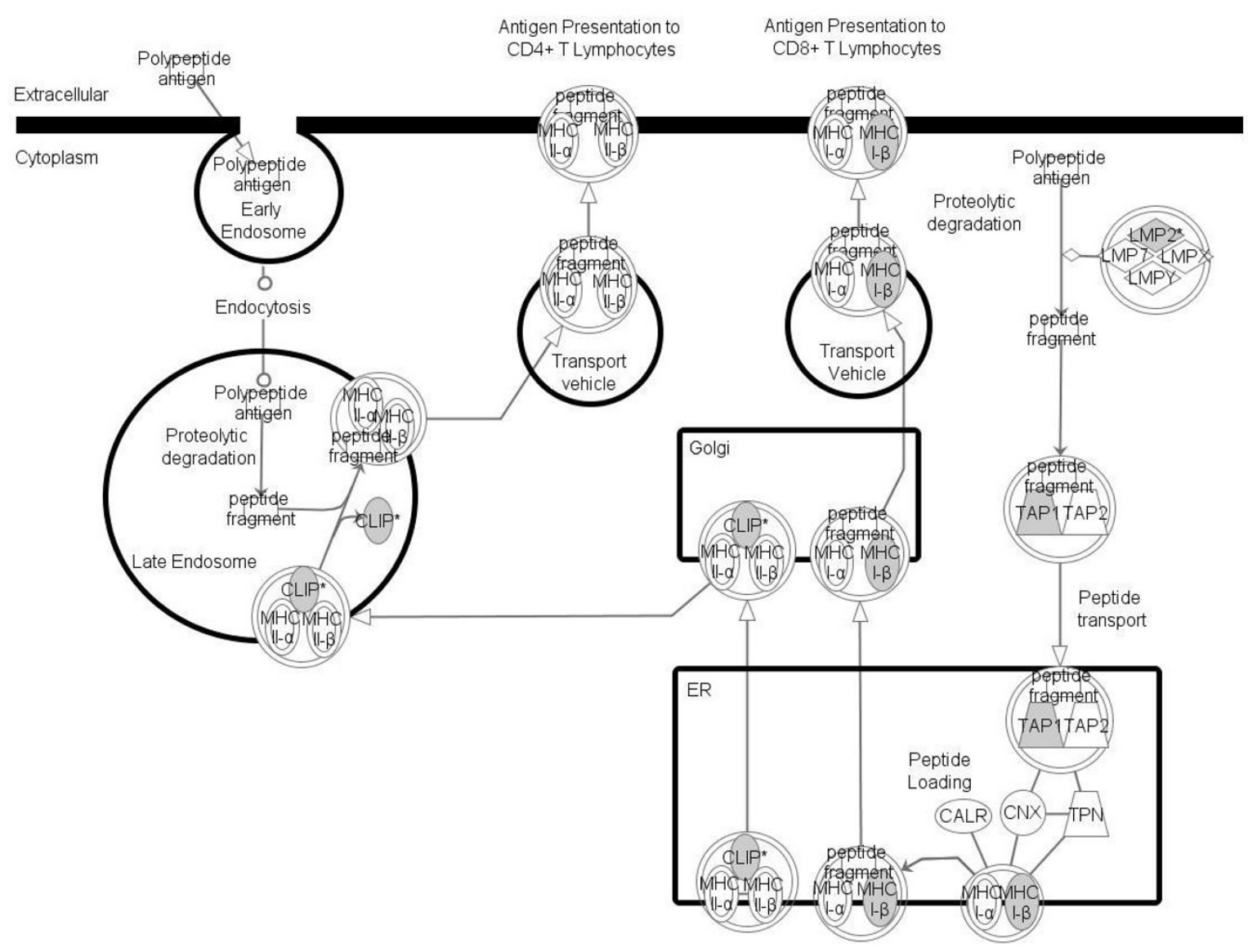

Figure 7

Significant pathways at the nominal $\mathbf{0 . 0 0}$ I level of the unpaired Student's t-test. The I top-scoring pathway of genes upregulated IPA image.

\section{Authors' contributions}

FMB, FI, MLT and FMM were responsible for the overall planning and coordination of the study. AW and LB were involved in the data analysis; VDG and EW were involved in genetic analyses. FI was involved in the patients enrollment and liver sample collection. VDG and AM were responsible for specimen processing and RNA analysis. VDG and FMB compiled and finalized the manuscript. All authors read and approved the final manuscript.

\section{Acknowledgements}

We are indebted to Dr. Marianna Sabatino for her invaluable technical support and fruitful discussions. This study was supported by grants from the Italian Ministry of Health - Ministero Italiano Salute (Ricerca Corrente 2008-9 and FSN 2005 Cnv 89).

\section{References}

I. El-Serag HB, Mason AC: Rising incidence of hepatocellular carcinoma in the United States. N Engl J Med I999, 340:745-750.
2. Davila JA, Petersena NJ, Nelson HA, El-Serag HB: Geographic variation within the United States in the incidence of hepatocellular carcinoma. J Clin Epidemiol 2003, 56:487-493.

3. El-Serag HB: Hepatocellular carcinoma and hepatitis $\mathbf{C}$ in the United States. Hepatology 2002, 36:S74-S83.

4. Romeo R, Colombo M: The natural history of hepatocellular carcinoma. Toxicology 2002, I 8I- | 82:39-42.

5. Block TM, Mehta AS, Fimmel CJ, Jordan R: Molecular viral oncology of hepatocellular carcinoma. Oncogene 2003, 22:5093-5I07.

6. Buendia MA: Hepatitis B viruses and cancerogenesis. Biomed Pharmacother 1998, 52:34-43.

7. Davis GL, Albright JE, Cook SF, Rosenberg DM: Projecting future complications of chronic hepatitis $\mathbf{C}$ in the United States. Liver Transpl 2003, 9:331-338.

8. Colombo M: The role of hepatitis $\mathbf{C}$ virus in hepatocellular carcinoma. Recent Results Cancer Res 1998, I54:337-344.

9. Ohata K, Hamasaki K, Toriyama K, Matsumoto K, Saeki A, Yanagi K, et al.: Hepatic steatosis is a risk factor for hepatocellular carcinoma in patients with chronic hepatitis $\mathbf{C}$ virus infection. Cancer 2003, 97:3036-3043.

10. Brunt EM: Nonalcoholic steatohepatitis. Semin Liver Dis 2004, 24:3-20.

II. Davila JA, Morgan RO, Shaib Y, McGlynn KA, El-Serag HB: Diabetes increases the risk of hepatocellular carcinoma in the United 
States: a population based case control study. Gut 2005, 54:533-539.

12. Fusco M, Girardi E, Piselli P, Palombino R, Polesel J, Maione C, et al.: Epidemiology of viral hepatitis infections in an area of southern Italy with high incidence rates of liver cancer. Eur J Cancer 2008, 44:847-853.

13. Schafer DF, Sorrell MF: Hepatocellular carcinoma. Lancet 1999, 353: $1253-1257$.

14. Levrero M: Viral hepatitis and liver cancer: the case of hepatitis C. Oncogene 2006, 25:3834-3847.

15. Macdonald GA, Greenson JK, Saito K, Cherian SP, Appelman HD, Boland CR: Microsatellite instability and loss of heterozygosity at DNA mismatch repair gene loci occurs during hepatic carcinogenesis. Hepatology 1998, 28:90-97.

16. Blum HE, Moradpour D: Viral pathogenesis of hepatocellular carcinoma. J Gastroenterol Hepatol 2002, I 7(Suppl 3):S4 I3-S420.

17. lizuka N, Oka M, Yamada-Okabe H, Mori N, Tamesa T, Okada T, et al.: Comparison of gene expression profiles between hepatitis $B$ virus- and hepatitis $C$ virus-infected hepatocellular carcinoma by oligonucleotide microarray data on the basis of a supervised learning method. Cancer Res 2002, 62:3939-3944.

18. Okabe H, Satoh S, Kato T, Kitahara O, Yanagawa R, Yamaoka Y, et al.: Genome-wide analysis of gene expression in human hepatocellular carcinomas using cDNA microarray: identification of genes involved in viral carcinogenesis and tumor progression. Cancer Res 200 I, 6I:2I 29-2I37.

19. Shirota Y, Kaneko S, Honda M, Kawai HF, Kobayashi K: Identification of differentially expressed genes in hepatocellular carcinoma with cDNA microarrays. Hepatology 200 I, 33:832-840.

20. Wang E, Miller LD, Ohnmacht GA, Liu ET, Marincola FM: High-fidelity mRNA amplification for gene profiling. Nat Biotechnol 2000, 1 8:457-459.

21. Eisen MB, Spellman PT, Brown PO, Botstein D: Cluster analysis and display of genome-wide expression patterns. Proc Natl Acad Sci USA 1998, 95: I4863-14868.

22. Ross DT, Scherf U, Eisen MB, Perou CM, Rees C, Spellman P, et al:: Systematic variation in gene expression patterns in human cancer cell lines. Nat Genet 2000, 24:227-235.

23. Nacht M, Ferguson AT, Zhang W, Petroziello JM, Cook BP, Gao YH, et al:: Combining serial analysis of gene expression and array technologies to identify genes differentially expressed in breast cancer. Cancer Res 1999, 59:5464-5470.

24. Sanchez-Carbayo M, Socci ND, Lozano JJ, Li W, Charytonowicz E, Belbin TJ, et al.: Gene discovery in bladder cancer progression using cDNA microarrays. Am J Pathol 2003, 163:505-516.

25. Safe S: Molecular biology of the Ah receptor and its role in carcinogenesis. Toxicol Lett 200 I, 120:1-7.

26. Okey $A B$ : An aryl hydrocarbon receptor odyssey to the shores of toxicology: the Deichmann Lecture, International Congress of Toxicology-XI. Toxicol Sci 2007, 98:5-38.

27. Puga $\mathrm{A}, \mathrm{Ma} \mathrm{C}$, Marlowe JL: The aryl hydrocarbon receptor cross-talks with multiple signal transduction pathways. Biochem Pharmacol 2009, 77:713-722.

28. Bock KW, Kohle C: Ah receptor- and TCDD-mediated liver tumor promotion: clonal selection and expansion of cells evading growth arrest and apoptosis. Biochem Pharmacol 2005, 69:1403-1408.

29. Tsunedomi R, lizuka N, Hamamoto $Y$, Uchimura S, Miyamoto T, Tamesa T, et al.: Patterns of expression of cytochrome P450 genes in progression of hepatitis $C$ virus-associated hepatocellular carcinoma. Int J Oncol 2005, 27:66I-667.

30. Pessione F, Ramond MJ, Njapoum C, Duchatelle V, Degott C, Erlinger $\mathrm{S}$, et al.: Cigarette smoking and hepatic lesions in patients with chronic hepatitis C. Hepatology 200I, 34: I2I-I25.

31. Hezode C, Lonjon I, Roudot-Thoraval F, Mavier JP, Pawlotsky JM, Zafrani ES, et al.: Impact of smoking on histological liver lesions in chronic hepatitis C. Gut 2003, 52:126-129.

32. Jentsch S, Pyrowolakis G: Ubiquitin and its kin: how close are the family ties? Trends Cell Biol 2000, 10:335-342.

33. Jesenberger $V$, Jentsch S: Deadly encounter: ubiquitin meets apoptosis. Nat Rev Mol Cell Biol 2002, 3: I I2-I2I.

34. Liu YC, Pan J, Zhang C, Fan W, Collinge M, Bender JR, et al.: A MHCencoded ubiquitin-like protein (FATIO) binds noncovalently to the spindle assembly checkpoint protein MAD2. Proc Natl Acad Sci USA 1999, 96:4313-4318.
35. Shah JV, Cleveland DW: Waiting for anaphase: Mad2 and the spindle assembly checkpoint. Cell 2000, 103:997-1000.

36. Wang X, Jin DY, Wong YC, Cheung AL, Chun AC, Lo AK, et al.: Correlation of defective mitotic checkpoint with aberrantly reduced expression of MAD2 protein in nasopharyngeal carcinoma cells. Carcinogenesis 2000, 21:2293-2297.

37. Gemma A, Hosoya Y, Seike M, Uematsu K, Kurimoto F, Hibino S, et al.: Genomic structure of the human MAD2 gene and mutation analysis in human lung and breast cancers. Lung Cancer 200I, 32:289-295.

38. Lee CG, Ren J, Cheong IS, Ban KH, Ooi LL, Yong TS, et al.: Expression of the FATI 0 gene is highly upregulated in hepatocellular carcinoma and other gastrointestinal and gynecological cancers. Oncogene 2003, 22:2592-2603.

39. Mas VR, Maluf DG, Archer KJ, Yanek K, Kong X, Kulik L, et al.: Genes involved in viral carcinogenesis and tumor initiation in hepatitis C virus-induced hepatocellular carcinoma. Mol Med 2009 , I 5:85-94.

40. Schuppan D, Krebs A, Bauer M, Hahn EG: Hepatitis C and liver fibrosis. Cell Death Differ 2003, I0(SuppI I):S59-S67.
Publish with Biomed Central and every scientist can read your work free of charge

"BioMed Central will be the most significant development for disseminating the results of biomedical research in our lifetime. "

Sir Paul Nurse, Cancer Research UK

Your research papers will be:

- available free of charge to the entire biomedical community

- peer reviewed and published immediately upon acceptance

- cited in PubMed and archived on PubMed Central

- yours - you keep the copyright 